\title{
3D-fabrication of tunable and high-density arrays of crystalline silicon nanostructures
}

\author{
J G E Wilbers ${ }^{1}$, J W Berenschot ${ }^{2}$, R M Tiggelaar ${ }^{2,3}$, T Dogan ${ }^{1}$, K Sugimura $^{4}$, \\ W G van der Wiel ${ }^{1}$, J G E Gardeniers ${ }^{2}$ and N R Tas ${ }^{2} \oplus$ \\ ${ }^{1}$ NanoElectronics Group, MESA + Institute for Nanotechnology, University of Twente, PO Box 217, \\ 7500 AE Enschede, Netherlands \\ ${ }^{2}$ Mesoscale Chemical Systems, MESA + Institute for Nanotechnology, University of Twente, PO Box \\ 217, 7500 AE Enschede, Netherlands \\ ${ }^{3}$ NanoLab cleanroom, MESA + Institute for Nanotechnology, University of Twente, PO Box 217, 7500 \\ AE Enschede, Netherlands \\ ${ }^{4}$ Toyota Technological Institute, 2-12-1 Hisakata, Tempaku-ku, Nagoya 468-8511, Japan \\ E-mail: n.r.tas@utwente.nl
}

Received 22 September 2017, revised 9 January 2018

Accepted for publication 29 January 2018

Published 15 February 2018

\begin{abstract}
In this report, a procedure for the 3D-nanofabrication of ordered, high-density arrays of crystalline silicon nanostructures is described. Two nanolithography methods were utilized for the fabrication of the nanostructure array, viz. displacement Talbot lithography (DTL) and edge lithography (EL). DTL is employed to perform two (orthogonal) resist-patterning steps to pattern a thin $\mathrm{Si}_{3} \mathrm{~N}_{4}$ layer. The resulting patterned double layer serves as an etch mask for all further etching steps for the fabrication of ordered arrays of silicon nanostructures. The arrays are made by means of anisotropic wet etching of silicon in combination with an isotropic retraction etch step of the etch mask, i.e. EL. The procedure enables fabrication of

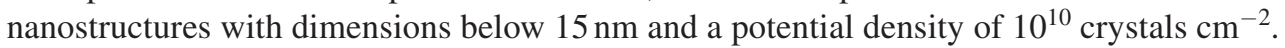

Keywords: nanocrystals, arrays, silicon, anisotropic etching, edge lithography, displacement Talbot lithography

S. Supplementary material for this article is available online

(Some figures may appear in colour only in the online journal)

\section{Introduction}

Silicon quantum dots (Si-QDs) are currently attracting a lot of attention due to their enormous application possibilities in the fields of quantum electronics, spintronics, photonics, photovoltaics, biology, and nonvolatile memories [1-4]. Porous silicon shows photoluminescence in the visible range and nanostructured silicon is expected to show increased photoluminescence due to quantum confinement [5-8]. The reason for the increased photoluminescence is that the indirect bandgap of bulk silicon could be altered into a direct bandgap in quantum confined silicon structures [9, 10]. Silicon nanocrystals can be synthesized by bottom-up as well as top-down fabrication techniques. Bottom-up methods include plasma based synthesis, solution-based synthesis, sol-gel based synthesis, and formation of a silicon-rich matrix (for example silicon oxide) followed by a high-temperature anneal [4]. Common top-down methods include mechanical 'crushing' followed by chemical etching, and electrochemical etching [4]. Depending on the preparation method, different strategies can be followed to obtain matrix-embedded and free-standing silicon nanocrystals. Most of the reported methods yield silicon nanostructures that are 'randomly' positioned, i.e. with a varying distance between adjacent crystals, which can also be considered as non-ordered or irregular arrays. Valenta et al [11] fabricated high-density arrays of Si-QDs by e-beam lithography (EBL) followed by Si nano-pillar etching, and a combination of thermal oxidation and hydrofluoric (HF) etching to decrease the size of the structures. In this report, we describe the topdown fabrication of high-density, single-crystalline silicon 
tetrahedral nanostructures with dimensions $<15 \mathrm{~nm}$ by wetchemical (an)isotropic etching for potential applications in optical sensing and electronics. The advantage of our topdown approach is the fact that the nanocrystals are fabricated in a highly-ordered array, and are not fully embedded in a scaffold. Therefore, they are accessible for making electrical contacts. Previously, Berenschot et al [12] reported on the top-down fabrication of single-crystalline silicon nanocrystals with dimensions down to $25 \mathrm{~nm}$ by wet-chemical anisotropic etching based on photolithographically machining of nanotetrahedra, with a density of $\sim 10^{7} / \mathrm{cm}^{2}$. For optical measurements a high amount of silicon nanocrystals on a given footprint is desirable, which is not achievable with standard UV-contact lithography. We report the development of ordered arrays with high-density nanostructures $\left(10^{10} / \mathrm{cm}^{2}\right)$, realized by combining wet-chemical (an)isotropic etching with DTL [13, 14]. Hereby, the amount of nanocrystals is increased to $10^{10} / \mathrm{cm}^{2}$, while their size is reduced to sub- $15 \mathrm{~nm}$.

V-grooves bounded by (111)-planes are etched in silicon using $\mathrm{Si}_{3} \mathrm{~N}_{4}$ as mask (pattern generated by DTL). The initial amount of $\mathrm{V}$-grooves is doubled by means of local oxidation of silicon (LOCOS), removal of the $\mathrm{Si}_{3} \mathrm{~N}_{4}$ mask, and a second anisotropic wet etching step. Anisotropic etching in combination with LOCOS has been reported for the fabrication of wedge-shaped emitters [15]. We elaborate on the tuning of the duty cycle of the doubled V-shaped grooves. This doubled $\mathrm{V}$-groove pattern in combination with a second nano-photolithographic line pattern - generated by DTL in an orthogonal fashion with respect to the initial V-grooves - and another two anisotropic wet etch steps yield ordered high-density arrays of crystalline silicon nanostructures. This procedure is explained in detail in section 2, while the fabrication results are shown and discussed in section 3 .

\section{Experimental methods}

In this work, we describe the fabrication of single-crystalline nanotetrahedra (in the following also called 'quantum dots' or 'nanocrystals'). This is done by utilizing a unique combination of two nano-lithography techniques, namely DTL and edge lithography (EL) [16]. It is noted that also the combination of DTL, EBL, corner lithography (CL) [17, 18], EL and silicon anisotropic wet-etching can be used to fabricate such nanocrystals, as shown in the supporting information (stacks. iop.org/JMM/28/044003/mmedia).

We started with a silicon (100) wafer with $10 \mathrm{~nm}$ silicon nitride $\left(\mathrm{Si}_{3} \mathrm{~N}_{4}\right)$ by low-pressure chemical vapor deposition (LPCVD). The wafer was subsequently patterned by the nanophotolithography technique 'displacement Talbot lithography' (PhableR $100 \mathrm{C}$ from Eulitha), which enables large-area, periodic sub-micrometer patterns. In short, a layer of photoresist (PFI88-diluted 1:1 in propylene glycol monomethyl ether acetate (PGMEA)) was patterned using different four exposure doses (i.e. 75, 85, 95, $105 \mathrm{~mJ}$ ), of which experimental details can be found elsewhere [19]. Underneath the resist a bottom layer anti-reflection coating (BARC; AZ Barli-II 200) was present. Each layer, i.e. the BARC and photoresist, has a thickness of $\sim 160 \mathrm{~nm}$. We patterned periodic lines of different line widths over an area of $3 \times 3 \mathrm{~cm}^{2}$. The resist line width and spacing can be tuned by the exposure dose. With a standard DTL exposure the lithographic duty cycle-defined as the ratio of the line widths of the photoresist ridge and spacer-can only be below 50\%. In this work, we elaborate on a method to tune this lithographic duty cycle to values of $50 \%$ (and larger) by utilizing metal lift-off and thereby inversion of the original resist pattern.

For transfer of the photoresist pattern into the BARC, the BARC layer was etched with reactive ion beam etching (RIBE) with oxygen $(20 \mathrm{sccm}, 180 \mathrm{~s})$ prior to etch the underlying $\mathrm{Si}_{3} \mathrm{~N}_{4}$. The $\mathrm{Si}_{3} \mathrm{~N}_{4}$ was etched by reactive ion etching (RIE) with a $\mathrm{CHF}_{3}: \mathrm{O}_{2}$ plasma according to the pattern by nano-photolithography ( 25 Watt, $25 \mathrm{sccm} \mathrm{CHF}_{3}, 5 \mathrm{sccm} \mathrm{O}_{2}$, 10 mTorr, $30 \mathrm{~s}$ ). After stripping the BARC and photoresist with an oxygen plasma, the exposed silicon areas (lines) were converted hydrophobic by $50 \%$ hydrogen fluoride (HF) etching (10s) to remove interfacial SiON/oxide. Subsequently $\mathrm{V}$-grooves were anisotropically etched using aqueous potassium hydroxide $(20 \mathrm{wt} \% \mathrm{KOH}$ at room temperature for 5:30 min, etch rate for Si (100): $20-25 \mathrm{~nm} \mathrm{~min}^{-1}$ ) using the structured $\mathrm{Si}_{3} \mathrm{~N}_{4}$ as an etch mask (figure 1(a)). The flat silicon (100) surface was converted into V-grooves bounded by two $\left\{\begin{array}{lll}1 & 1 & 1\end{array}\right\}$ planes according to the $\mathrm{Si}_{3} \mathrm{~N}_{4}$ pattern [15]. The periodicity of these $\mathrm{V}$-grooves can straightforwardly be doubled. LOCOS at $900{ }^{\circ} \mathrm{C}$ for $35 \mathrm{~min}$ (resulting in $21 \mathrm{~nm} \mathrm{SiO}_{2}$ on $\mathrm{Si}\left\langle\begin{array}{lll}1 & 1 & 1\end{array}\right)$ was used to protect the already etched V-grooves and the sample was etched in $1 \% \mathrm{HF}(20 \mathrm{~s})$ to strip the thin oxide layer from $\mathrm{Si}_{3} \mathrm{~N}_{4}$, subsequently in phosphoric acid $(85 \%$ $\mathrm{H}_{3} \mathrm{PO}_{4}, 140{ }^{\circ} \mathrm{C}, 13 \mathrm{~min}$ ) to remove the $\mathrm{Si}_{3} \mathrm{~N}_{4}$ and again in $1 \%$ $\mathrm{HF}$ to dissolve the interfacial layer underneath the $\mathrm{Si}_{3} \mathrm{~N}_{4}$ from the silicon substrate (i.e. to render the surface hydrophobic (figure 1(b))). A 2nd anisotropic etching step was done for $1 \mathrm{~min}$ in tetramethylammonium hydroxide (25\% TMAH, 70 ${ }^{\circ} \mathrm{C}$; etch rate for Si (100): $0.3 \mu \mathrm{m} \mathrm{min}{ }^{-1}$ and for Si (1 111$)$ : $15-20 \mathrm{~nm} \mathrm{~min}^{-1}$ [20]) to double the V-groove pattern (figure 1(c)). After doubling of the V-grooves the remaining oxide was stripped in $50 \% \mathrm{HF}$ (figure 1(d)). $19 \mathrm{~nm}$ of $\mathrm{Si}_{3} \mathrm{~N}_{4}$ was deposited by LPCVD (figure 1(e)). In fact, although the lithographic duty cycle is below $50 \%$, a $50 \%-50 \%$ duty cycle of the doubled V-groove pattern-defined as the widths of the $\mathrm{V}$-grooves etched in the 1st step $(\mathrm{KOH})$ and 2nd step (TMAH) — can be accomplished by means of optimizing the etching time in TMAH (as shown in figure 1(c)); details will be discussed in section 3.2).

In the second patterning step, the etched V-grooves were first planarized by spinning a BARC layer. Then a PFI88 resist layer was spin coated. Patterning with $90^{\circ}$ rotation with respect to the length direction of the V-grooves was performed by DTL, followed by a modified lift-off procedure using a $10 \mathrm{~nm}$ e-beam deposited Cr layer (figure 2(a)). Details of this modified lift-off procedure will be given below. For the fabrication of periodic Si nanocrystals based on two orthogonal exposures by DTL, it is essential to achieve a lithographic duty cycle of $50 \%$ in this second patterning step. In the case of duty cycles other than $50 \%$, the nanocrystals will not be equally distributed and two nanocrystals will be formed in 
a)

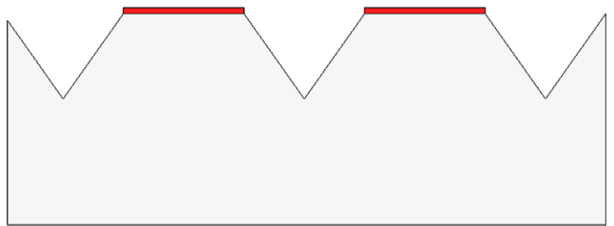

b)

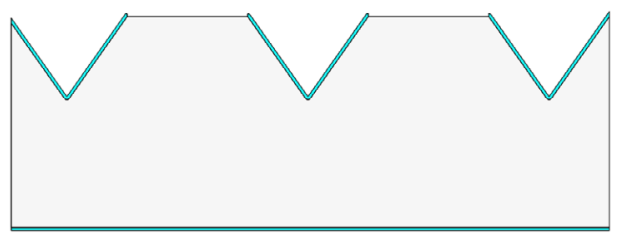

c)

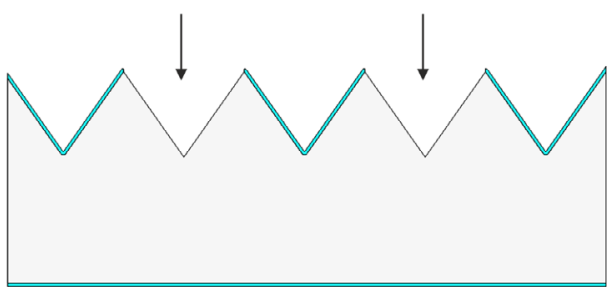

e)

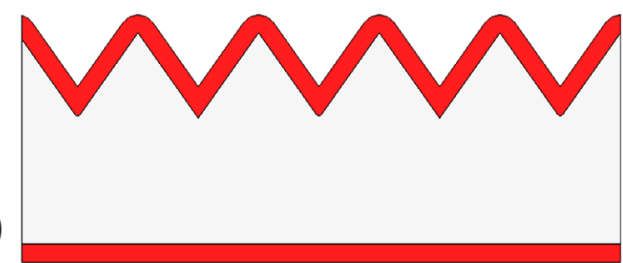

d)
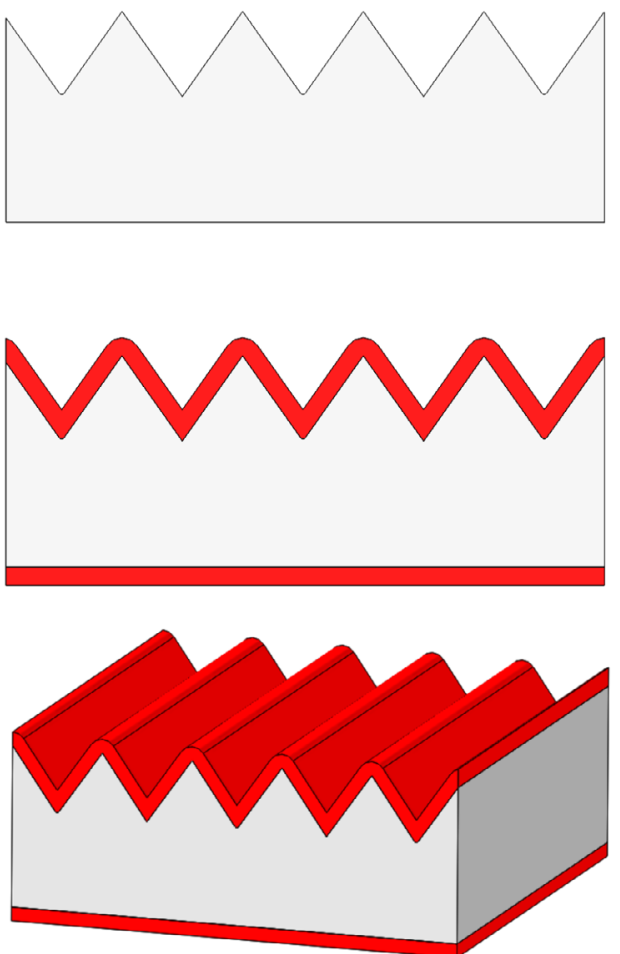

Figure 1. Schematic representation of the realization of doubled V-grooves [15]. (a) Patterning of the silicon $(100)$ wafer with $10 \mathrm{~nm} \mathrm{Si}_{3} \mathrm{~N}_{4}$ by DTL, and $\mathrm{KOH}$ etching of V-grooves using $\mathrm{Si}_{3} \mathrm{~N}_{4}$ as mask; (b) LOCOS followed by stripping of $\mathrm{Si}_{3} \mathrm{~N}_{4}$; (c) doubling of the V-grooves using TMAH; (d) oxide stripping (e) LPCVD of $\mathrm{Si}_{3} \mathrm{~N}_{4}$.
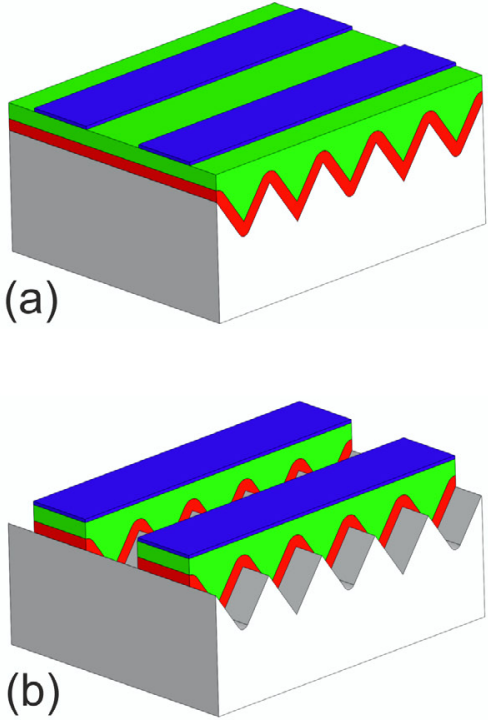

(d)
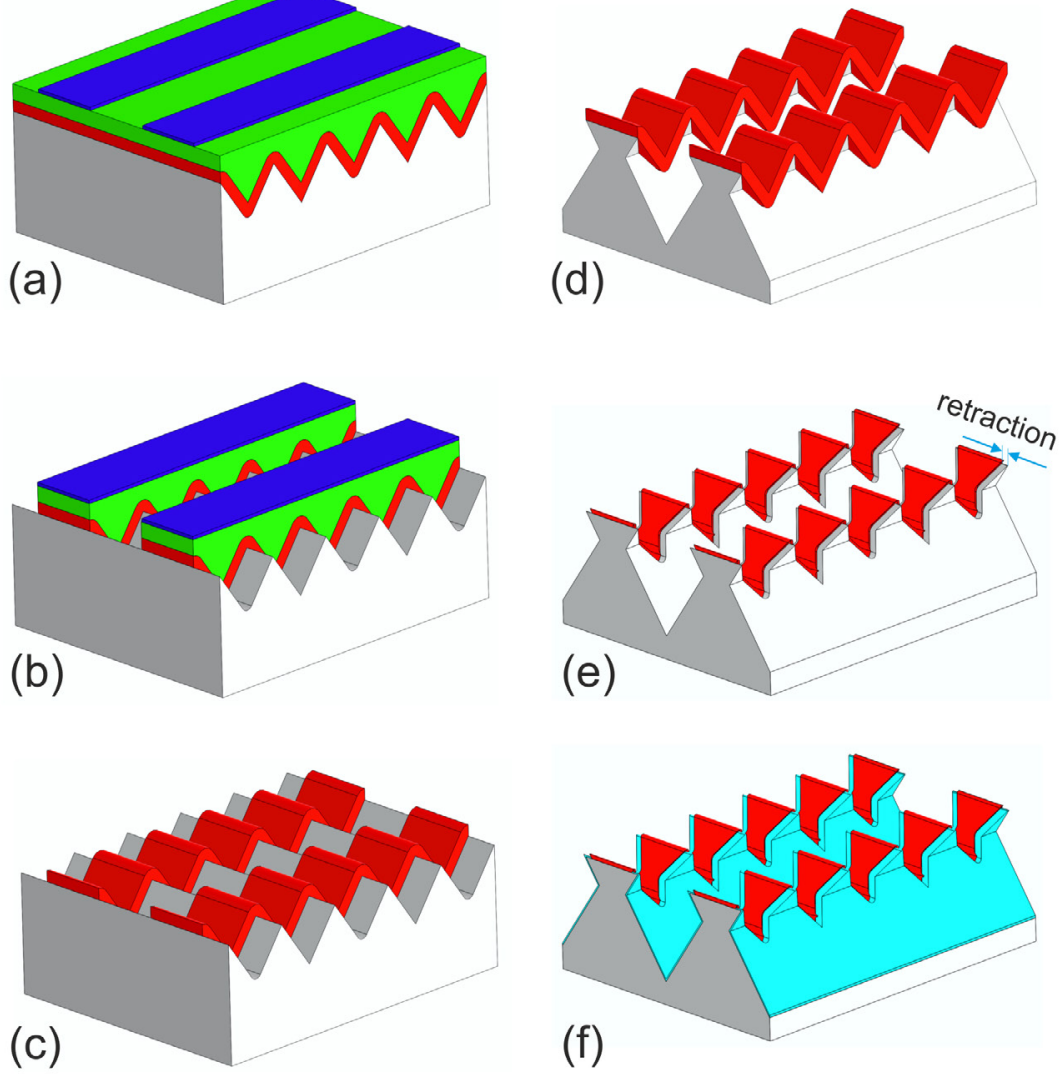

(g)

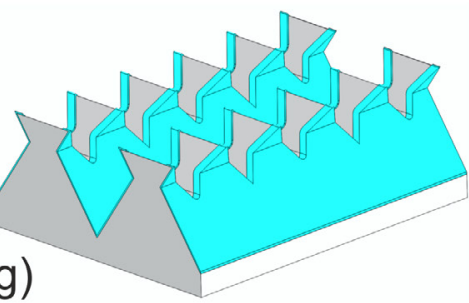

(h)

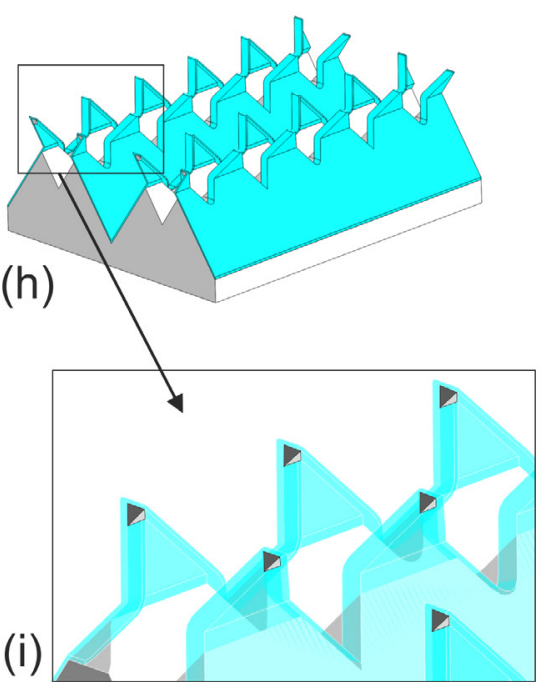

Figure 2. Schematic of the Si nanocrystal fabrication. (a) doubled V-grooves with $\mathrm{Si}_{3} \mathrm{~N}_{4}, \mathrm{Cr}$-stripes on BARC, $90^{\circ}$ rotated with respect to the V-grooves; (b) BARC and $\mathrm{Si}_{3} \mathrm{~N}_{4}$ layer patterning by RIE; (c) stripping of $\mathrm{Cr}$ and BARC; (d) anisotropic etching in $\mathrm{KOH}$ (e) retraction of $\mathrm{Si}_{3} \mathrm{~N}_{4}$ by EL; (f) LOCOS; (g) selective etching of $\mathrm{Si}_{3} \mathrm{~N}_{4}$; (h) anisotropic etching in $\mathrm{KOH}$ creating silicon nanocrystals; (i) zoom-in on the $\mathrm{Si}$ nanocrystals embedded in $\mathrm{SiO}_{2}$ from three sides bounding by $\left\{\begin{array}{lll}1 & 1 & 1\end{array}\right\}$ planes. 


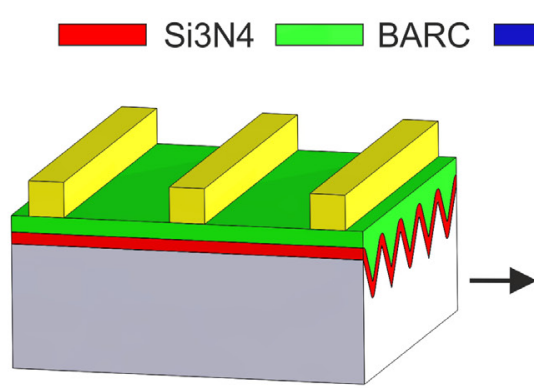

(a)

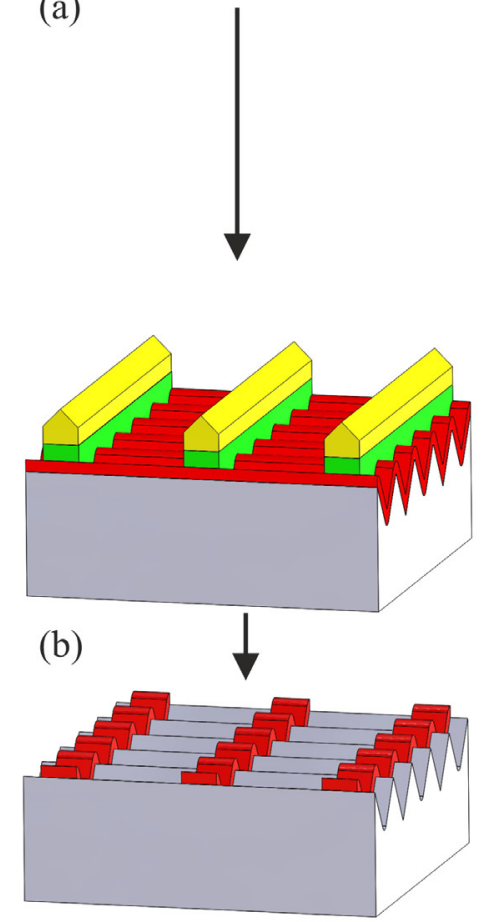

(c)
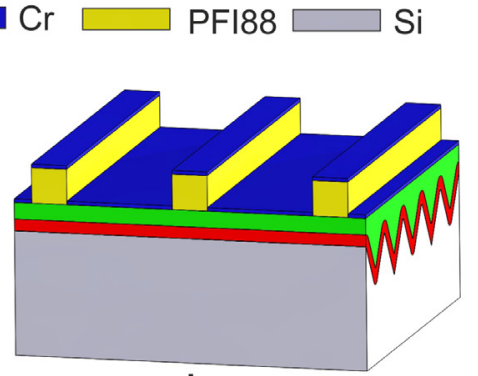

(d)

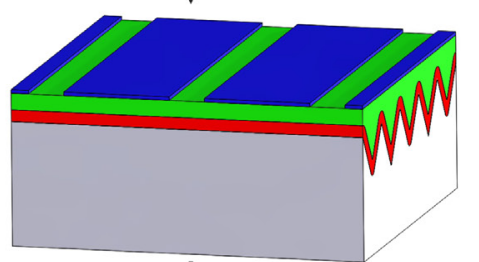

(e)

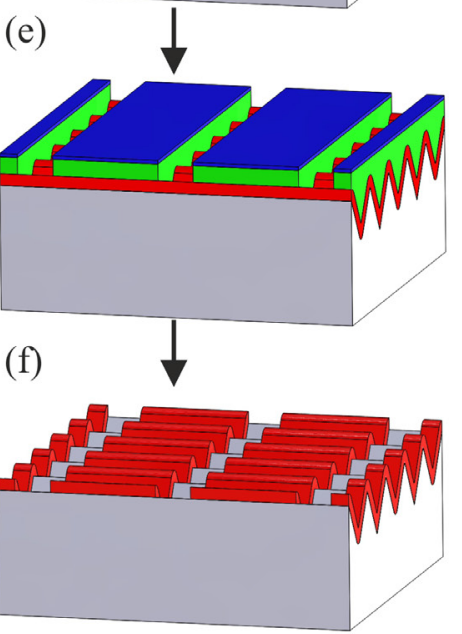

(g)

Figure 3. Lithographic duty cycle $<50 \%$ for DTL-standard ((a)-(c)) and $\geqslant 50 \%$ DTL-Cr ((a), (d)-(g)).

close proximity to each other which can even hinder the formation of nanocrystals if the in-between distance is too small. A modified chromium lift-off method is introduced to achieve the required duty cycle. After the second DTL-patterning step and this lift-off method, RIE was used to pattern the $\mathrm{Si}_{3} \mathrm{~N}_{4}$ using the same etch conditions as after the first DTL patterning step (figure 2(b)). After stripping the $\mathrm{Cr}$-mask in standard $\mathrm{Cr}$ etchant, stripping the BARC layer in $100 \% \mathrm{HNO}_{3}$, (figure $2(c)$ ) and removal of the interfacial $\mathrm{SiO}_{2}$ layer in $50 \% \mathrm{HF}$ for $15 \mathrm{~s}$, the patterned $\mathrm{Si}_{3} \mathrm{~N}_{4}$ was utilized as mask for anisotropic etching of the exposed silicon areas in $\mathrm{KOH}(20 \mathrm{wt} \%$ at room temperature for 5:30 min, etch rate of Si (100): 20$25 \mathrm{~nm} \mathrm{~min}{ }^{-1}$ ) (figure 2(d)). New $\{111\}$ planes were thereby released under the $\mathrm{Si}_{3} \mathrm{~N}_{4}$ mask. The etching is terminated by the $\{111\}$ planes that are pinned under the vertex which is formed by the top of the first etched and by silicon nitride protected V-grooves. The second $\{111\}$ planes are originating from the pinning of the (111) plane with the bottom line of the first etched V-grooves [12]. We then continued the fabrication with so called EL, i.e. retraction of $\mathrm{Si}_{3} \mathrm{~N}_{4}$ [16]. For this isotropic etch, $50 \% \mathrm{HF}$ was used because of the high selectivity with respect to silicon (figure 2(e)). The silicon nitride pull-back process strongly depends on the geometry of the anisotropically etched silicon. The size of the nanocrystal that will later be formed is determined by the length of the pullback of silicon nitride and the slow etch rate of $\mathrm{Si}\{111\}$. In this work the pull-back length was ca. $10 \mathrm{~nm}$. The exposed Si $\left\{\begin{array}{lll}1 & 1 & 1\end{array}\right\}$ planes were locally dry oxidized (LOCOS) at $1050{ }^{\circ} \mathrm{C}$ for $1 \mathrm{~min}$, resulting in an oxide thickness of $13.9 \mathrm{~nm} \pm 0.5 \mathrm{~nm}$ (measured on a (111) Si dummy wafer). A dry-oxidation temperature of $1050{ }^{\circ} \mathrm{C}$ was chosen because conformal oxidation will occur at convex apices. Temperatures lower than 960 ${ }^{\circ} \mathrm{C}$ will cause sharpening of the apices where higher temperatures than $1050{ }^{\circ} \mathrm{C}$ results in rounded apices [21]. Then the $\mathrm{Si}_{3} \mathrm{~N}_{4}$ was selectively removed in $\mathrm{H}_{3} \mathrm{PO}_{4}\left(85 \%\right.$, at $140{ }^{\circ} \mathrm{C}$ for $25 \mathrm{~min}$, etch rate of $\mathrm{Si}_{3} \mathrm{~N}_{4}: 0.7 \mathrm{~nm} \mathrm{~min}{ }^{-1}$; native oxide was stripped in $1 \% \mathrm{HF}$ in advance) (figures $2(\mathrm{f})$ and $(\mathrm{g})$ ). The last (4th) anisotropic etching step was again done in $20 \mathrm{wt} \% \mathrm{KOH}$ at room temperature for $180 \mathrm{~s}$ and resulted in the creation of the silicon nanocrystals (figures $2(\mathrm{~h})$ and (i)). It is important that the native oxide was properly removed before etching of silicon, otherwise the etch process will not start in $\mathrm{KOH}$. The resulting structures are freestanding $\mathrm{SiO}_{2}$ patterns from LOCOS, with the silicon nanotetrahedra embedded in the tips. 

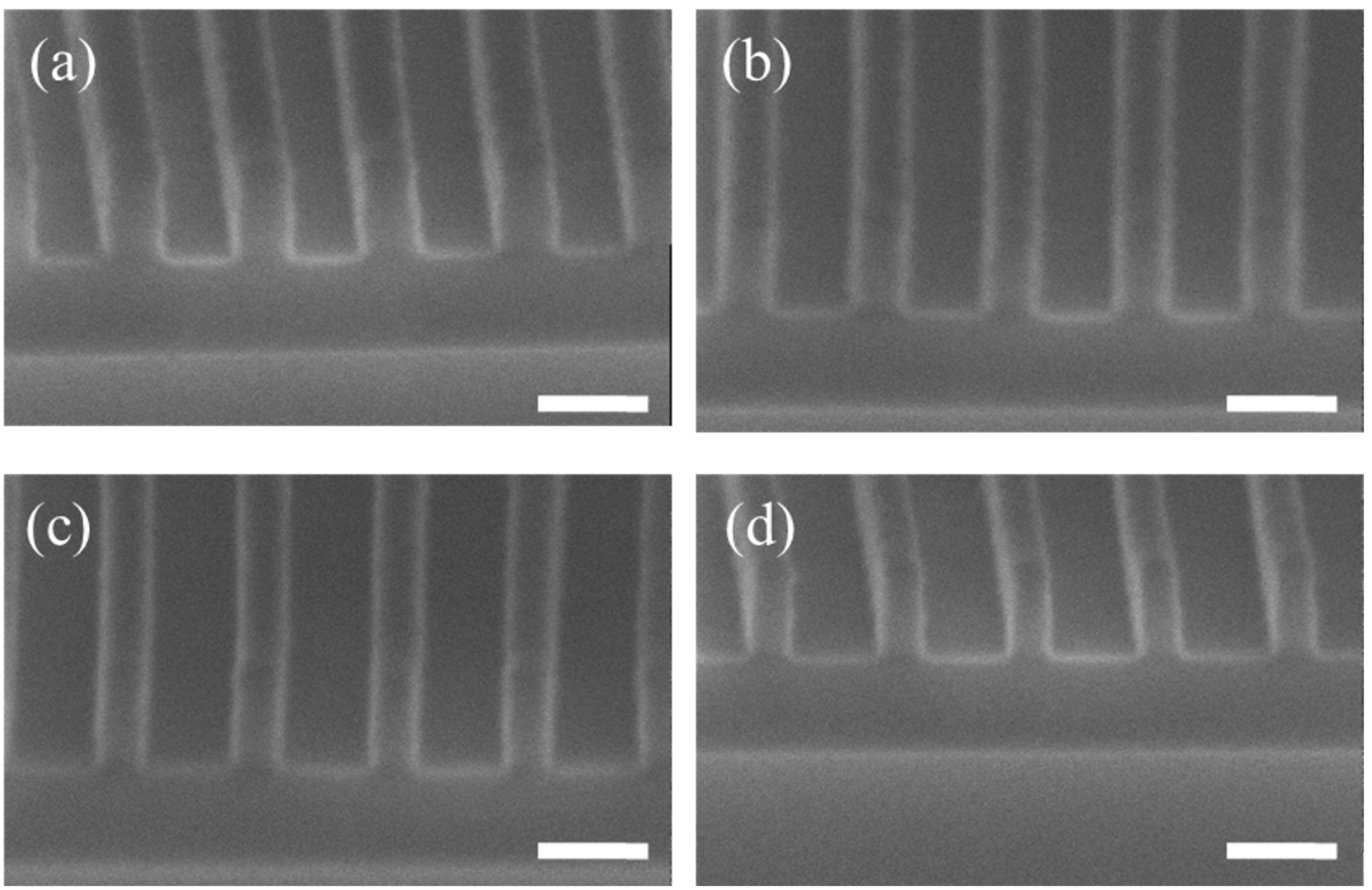

Figure 4. SEM images of typical line patterns defined in the photoresist (with BARC) by displacement Talbot lithography for exposure doses of (a) $75 \mathrm{~mJ}$ (spacer width: $130 \pm 14 \mathrm{~nm}$, PR line width: $117 \pm 13 \mathrm{~nm}$ ), (b) $85 \mathrm{~mJ}$ (spacer width: $148 \pm 8 \mathrm{~nm}$, PR line width: $96 \pm 7 \mathrm{~nm}$ ), (c) $95 \mathrm{~mJ}$ (spacer width: $161 \pm 5 \mathrm{~nm}$, PR line width: $86 \pm 7 \mathrm{~nm}$ ) and (d) $105 \mathrm{~mJ}$ (spacer width: $167 \pm 7 \mathrm{~nm}$, PR line width: $77 \pm 11 \mathrm{~nm}$ ). (scale bar: $200 \mathrm{~nm})$.
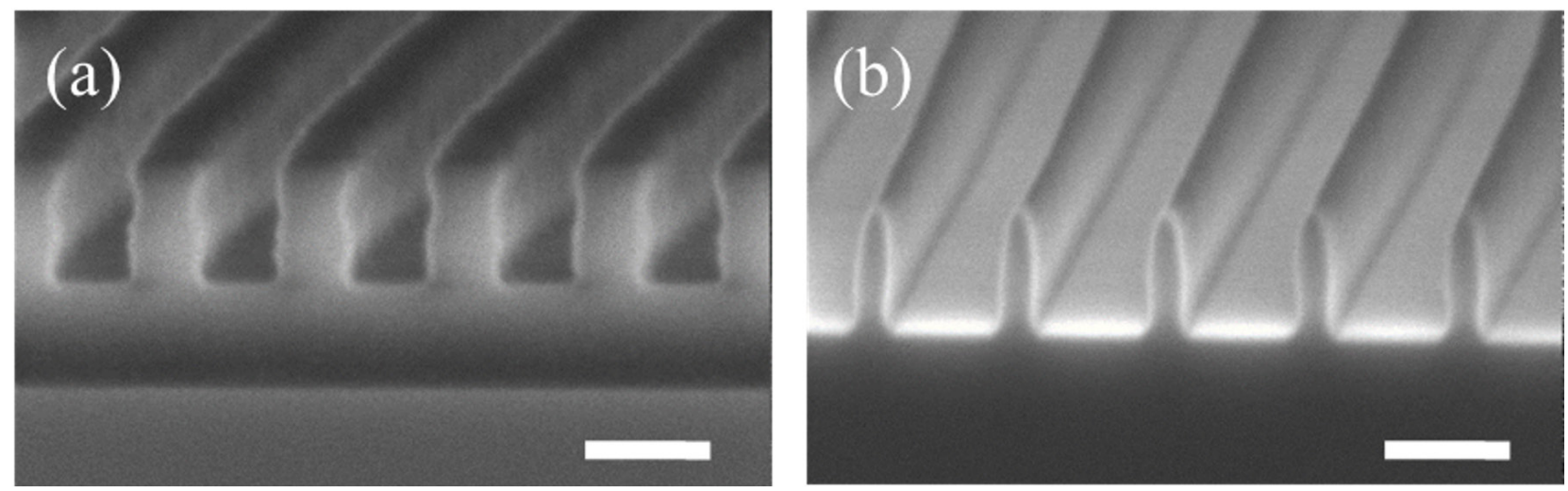

Figure 5. SEM images of the line pattern in PFI88-Barli-II (a) prior and (b) post to treatment with RIBE for 3.5 min. The exposure dose of the photoresist was $75 \mathrm{~mJ}$ which corresponds to a spacer width of $130 \pm 14 \mathrm{~nm}$ and PR line width of $117 \pm 13 \mathrm{~nm}$. After RIBE the measured spacer width was $167 \pm 7 \mathrm{~nm}$ and the PR line width was $77 \pm 11 \mathrm{~nm}$. (scale bar is $200 \mathrm{~nm}$ ).

The tetrahedral nanocrystals are surrounded from three sides by oxide.

Some aspects of the 2nd line patterning step have to be highlighted, in particular how a 50\%-50\% duty cycle can be obtained. The following section and figure 3 clarify the differences between the first (standard) DTL line patterning step in comparison with the 2nd line patterning step based on DTL and $\mathrm{Cr}$ lift-off, a combination that yields an inversion of the original resist pattern.

In figures 3(a)-(c) the standard DTL procedure is shown: post to exposure and development (figure 3(a)), directional etching of the BARC layer (figure 3(b)) is performed, followed by RIE of $\mathrm{Si}_{3} \mathrm{~N}_{4}$ and stripping the BARC and PFI88 (figure $3(\mathrm{c})$ ). In this way only lithographic duty cycles $<50 \%$ can be obtained. In order to have the preferred $50 \%-50 \%$ duty cycle, a combination of DTL and metal lift-off is required, as shown in figures $3(\mathrm{~d})-(\mathrm{g})$. This so-called DTL-Cr procedure is utilized for generation of the 2nd line pattern. For the definition of the 2nd line pattern BARC (AZ Barli-II 200) and photoresist (PFI88-diluted 1:1 in PGMEA) are spin-coated using the same parameters as for the first nanolithographic patterning step (i.e. 1st V-groove definition step). The phase shift-line 
(a)

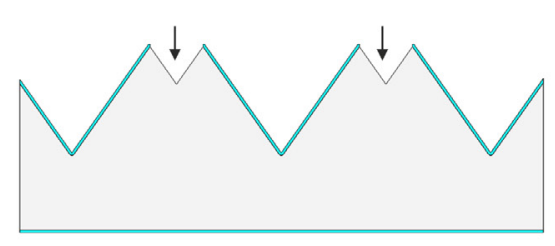

(b)
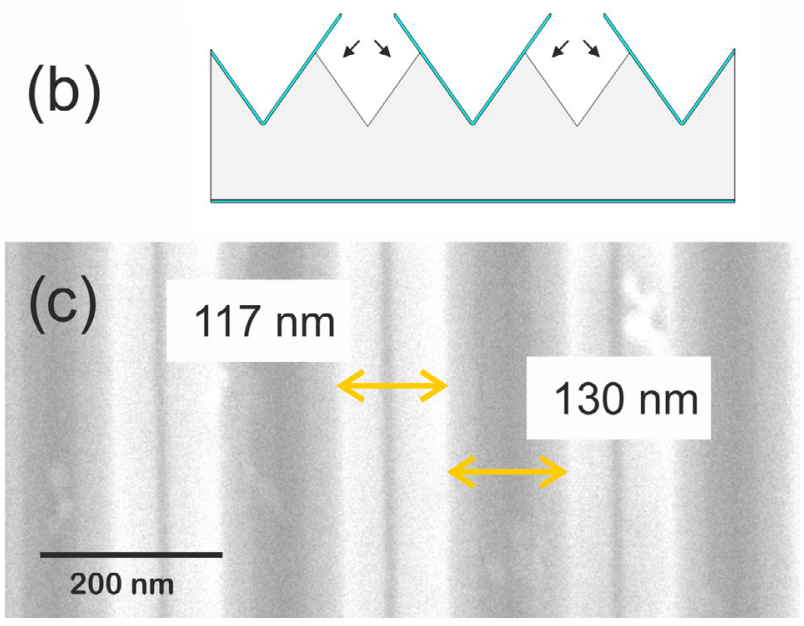
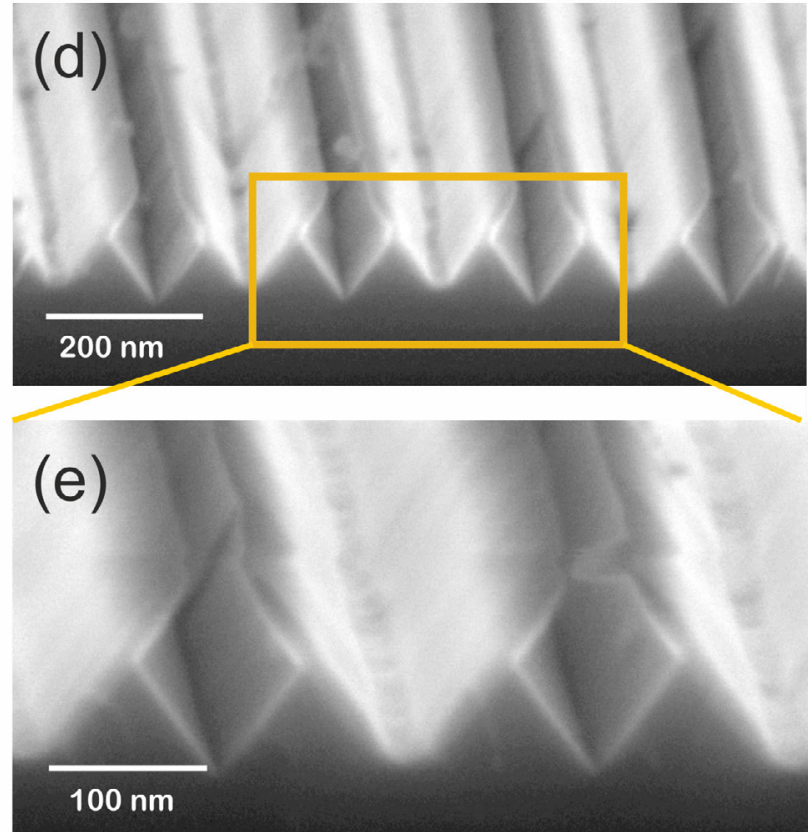

Figure 6. Tuning of the duty cycle of the second generation V-grooves formed by TMAH. (a) shallow TMAH etched V-grooves after 1 min etching in TMAH; (b) duty cycle of $50 \%$ after 6 min of TMAH etching with corresponding SEM images of the V-grooves in top view, with initial line and space of $117 \mathrm{~nm}$ and $130 \mathrm{~nm}$, respectively (c) and as a cross section ((d) and (e)).

(a)

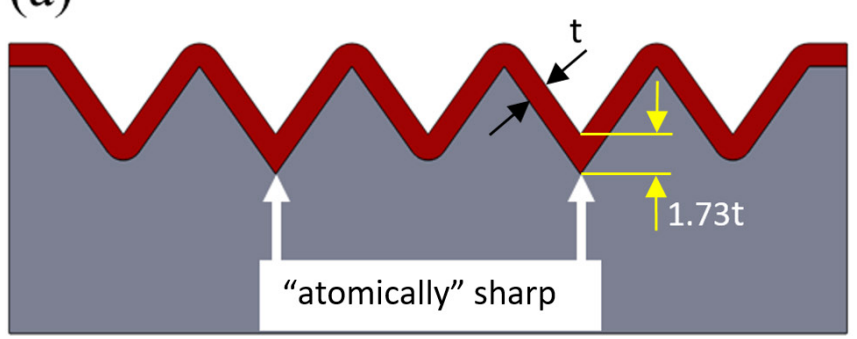

(b)

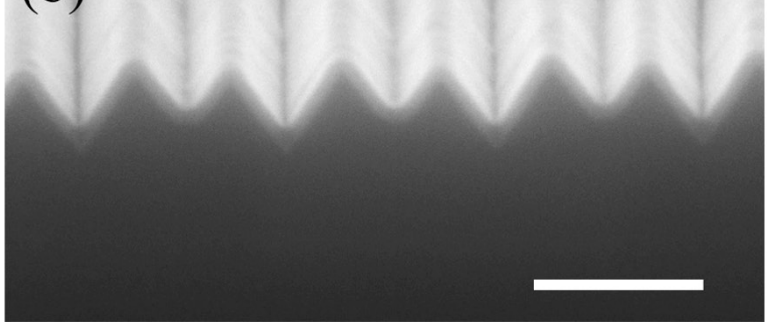

Figure 7. Cross-sectional scheme (a) and SEM image (b) of doubled V-grooves with $\mathrm{Si}_{3} \mathrm{~N}_{4}$ layer with alternating rounded and sharp grooves after two DTL steps. KOH etched V-grooves have a rounded bottom due to LOCOS while TMAH etched V-grooves are sharp. Scale bar is $200 \mathrm{~nm}$.

mask with a periodicity of $500 \mathrm{~nm}$ is rotated $90^{\circ}$ with respect to the first pattern and the resist is exposed at $1 \mathrm{~mW}$ with a dose of $105 \mathrm{~mJ}$, the target cycle is $20 \mathrm{~s}$ with one precycle, a polarizer is used, the DTL-range is $3 \mu \mathrm{m}$ and the gap between the wafer and the mask is $\sim 65 \mu \mathrm{m}$. Subsequently, the resist is baked for $1 \mathrm{~min}$ at $110^{\circ} \mathrm{C}$ and developed in Olin OPD 4262 for $1 \mathrm{~min}$ (figure 3(a)). After development a flood exposure is performed to make the remaining resist pattern dissolvable and thus applicable for a lift-off procedure. Then a $10 \mathrm{~nm}$ thin Cr layer is deposited using e-beam evaporation (figure 3(d)) and a lift-off procedure is performed in OPD 4262 in an ultrasonic bath for $20 \mathrm{~min}$ (figure 3(e)). The remaining BARC layer is removed by dry etching with an $\mathrm{N}_{2}$ plasma for 9:30 min [19] (figure 3(f)). With this Cr lift-off sequence a duty cycle of $50 \%$ of the line pattern can be achieved, whereas direct utilization of the BARC/photoresist pattern does not result in such lithographic duty cycle. The line pattern is inverted by utilizing the $\mathrm{Cr}$ lift-off procedure, which means the areas where the photoresist originally remained are etched. To summarize, a duty cycle of $50 \%$ and larger can only be achieved with this
DTL-Cr procedure, and not with the standard DTL line patterning step that directly utilized the photoresist pattern (see results and discussion part).

\section{Results and discussion}

\subsection{Fabrication of line patterns of photoresist}

In figure 4, scanning electron microscopy (SEM) images of line patterns in the photoresist with $250 \mathrm{~nm}$ periodicity are shown for different exposure doses. The variation of the exposure dose enables the tuning of the lines and their spacing. The photoresist lines cannot be wider than half of the period since an underexposure is not possible because the resist pattern will not become fully opened in that case. Overexposure on the other hand is possible, resulting in smaller lines and wider spacings. For all used exposure doses steep, vertical resist patterns were observed independent of the development time.

The transfer of the line pattern in the photoresist layer into the BARC was done by RIBE $\left(5 \mathrm{sccm} \mathrm{Ar}, 10 \mathrm{sccm} \mathrm{O}_{2}\right.$, 

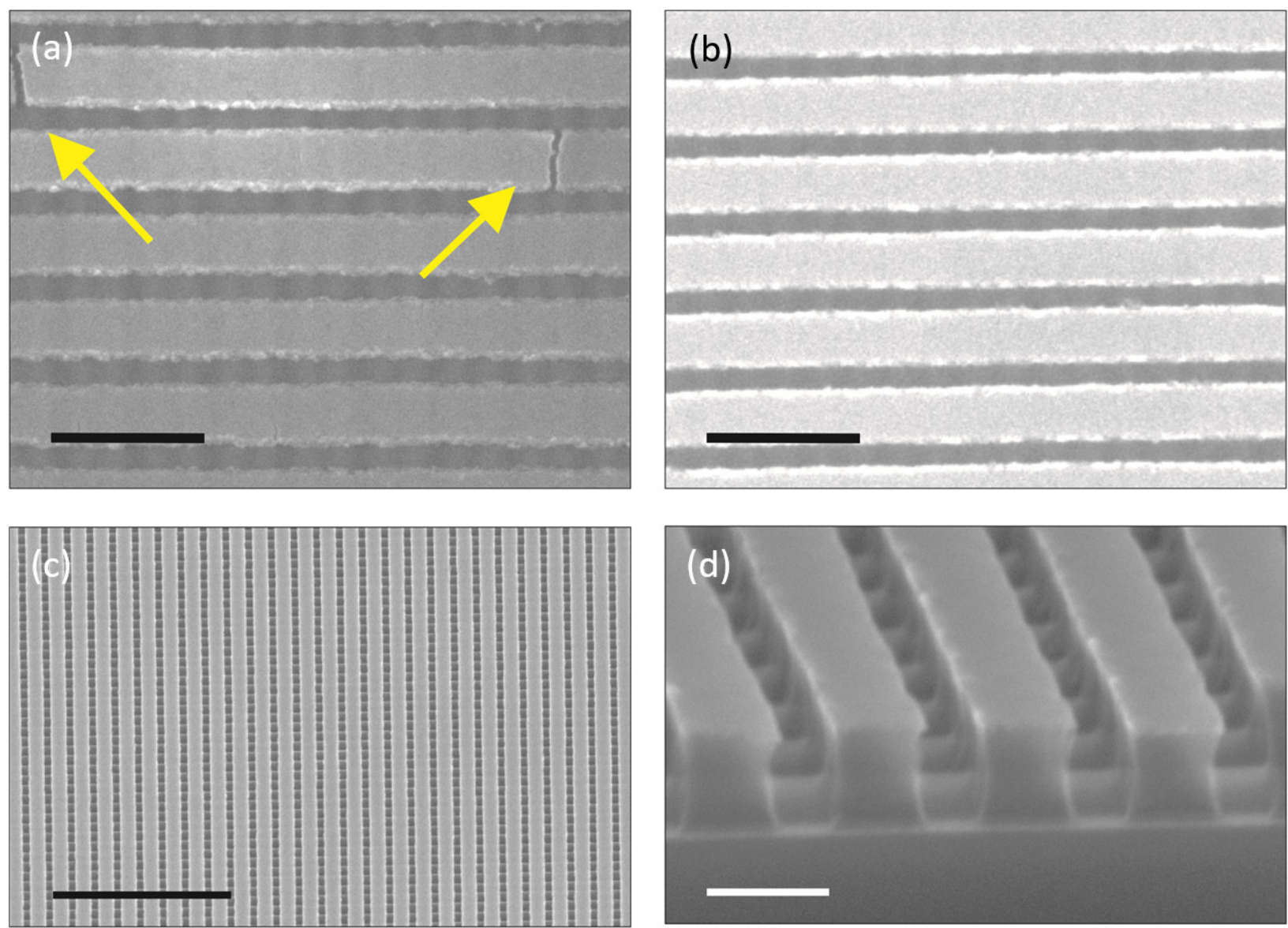

Figure 8. Effect of the thickness of the evaporated chromium layer on the outcome of the alternative lift-off procedure prior to BARC etching: (a) $20 \mathrm{~nm}$ shows cracks (indicated with arrows), (b) $10 \mathrm{~nm}$ (no defects/cracks in metal pattern). (c) Top view image after RIE etching of the BARC layer with $\mathrm{N}_{2}$. The underlying V-grooves from the 1 st DTL patterning step (with $90^{\circ}$ rotation with respect to the lines from the 2nd DTL step) are clearly visible. (d) Corresponding cross-section. Scale bar in (a) and (b) is $500 \mathrm{~nm}$, in (c) $2 \mu \mathrm{m}$ and in (d) $200 \mathrm{~nm}$.

50-55 mA). RIBE results in widening of the spacer width and decreased resist ridge widths (see figure 5). The photoresist ridge width defined in the photoresist/BARC layers decreased linearly with ca. $17.5 \mathrm{~nm} \mathrm{~min}^{-1}$ and correspondingly the spacer widths increased with this rate. For the $250 \mathrm{~nm}$ periodicity line patterns an etch rate (in vertical direction) of $35 \pm 4 \mathrm{~nm} \mathrm{~min}^{-1}$ was found for the photoresist and $44 \mathrm{~nm} \mathrm{~min}^{-1}$ for the BARC.

\subsection{Fabrication of V-grooves by anisotropic wet etching}

The first generation of $\mathrm{V}$-grooves is aligned with respect to the crystal orientation of $\mathrm{Si}$ [22]. In figure 6 the tuning of the duty cycle of the doubled V-grooves is shown schematically and with corresponding SEM images. The photoresist pattern cannot be 1:1 transferred into the BARC layer as discussed above which means that the ridges will always have a smaller width compared to the spacings after RIBE. However, a 50\%:50\% duty cycle of the doubled V-grooves-i.e. the ratio of the widths of the V-grooves etched in the first step (KOH) and second step (TMAH) — can still be achieved by tuning of the $\left\{\begin{array}{lll}1 & 1 & 1\end{array}\right\}$ planes. For exposure of the photoresist a dose of 75 $\mathrm{mJ}$ was used resulting in spacings of $130 \mathrm{~nm}$ and line widths of $117 \mathrm{~nm}$. The depth of the second generation V-grooves and thus the duty cycle of the etched V-grooves can be controlled by the etching time of the TMAH-step. A short TMAH etch of 1 min resulted in quite shallow second $\mathrm{V}$-grooves. We tuned the duty cycle of the zig-zag structures to $50 \%$ by an additional 5 min of etching.

Upon more detailed inspection of the doubled V-groove pattern, it becomes clear that the shape of the bottom of the V-grooves differs between the first anisotropic and second etching step, which is due to the LOCOS step that is only applied to the first generation V-grooves. From the high-resolution SEM image of the cross section of a sample with a conformal deposited $\mathrm{Si}_{3} \mathrm{~N}_{4}$ layer (figure 7) it can be seen that every first generation groove ( $\mathrm{KOH}$-etched) has a rounded silicon mold, in contrast to second generation (TMAH etched) V-grooves with 'atomically' sharp $\langle 111\rangle$ plane intersections next to it. We attribute this to the LOCOS step prior to the doubling of the V-grooves, which causes rounding of anisotropically etched V-grooves in silicon [23].

\subsection{Fabrication of orthogonal line patterns}

From the SEM images in figure 5 it can be seen that a duty cycle of $50 \%$ cannot be achieved with solely PFI88-Barli-II, because the line width of the remaining photoresist after etching of the underlying BARC layer becomes too narrow 
(a)

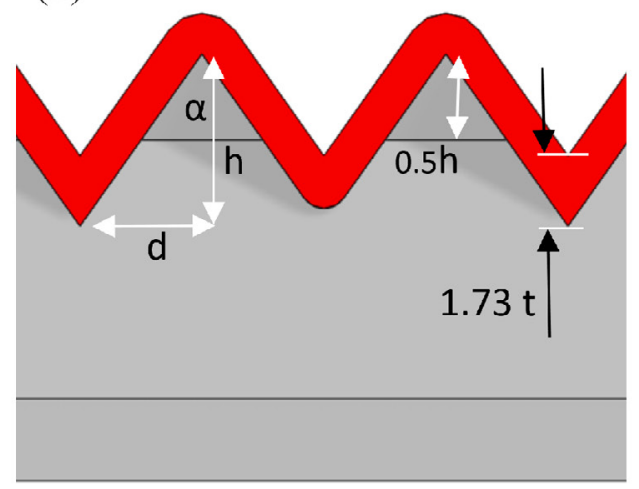

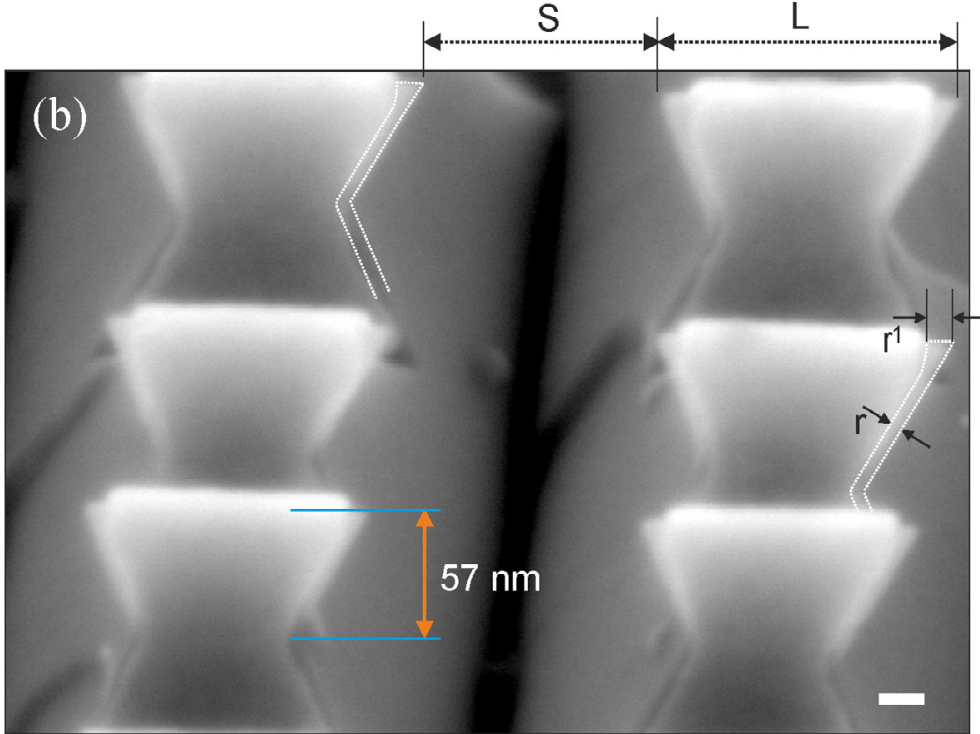

Figure 9. (a) Expected geometry after the third $\mathrm{KOH}$ etching step and (b) SEM image of etched anvil structures after the retraction EL of $7.9 \mathrm{~nm} \mathrm{Si}_{3} \mathrm{~N}_{4}\left(90^{\circ}\right.$ rotated view compared to (a) and $45^{\circ}$ tilted). White dotted lines indicate the amount of retraction. Scale bar is $20 \mathrm{~nm}$.

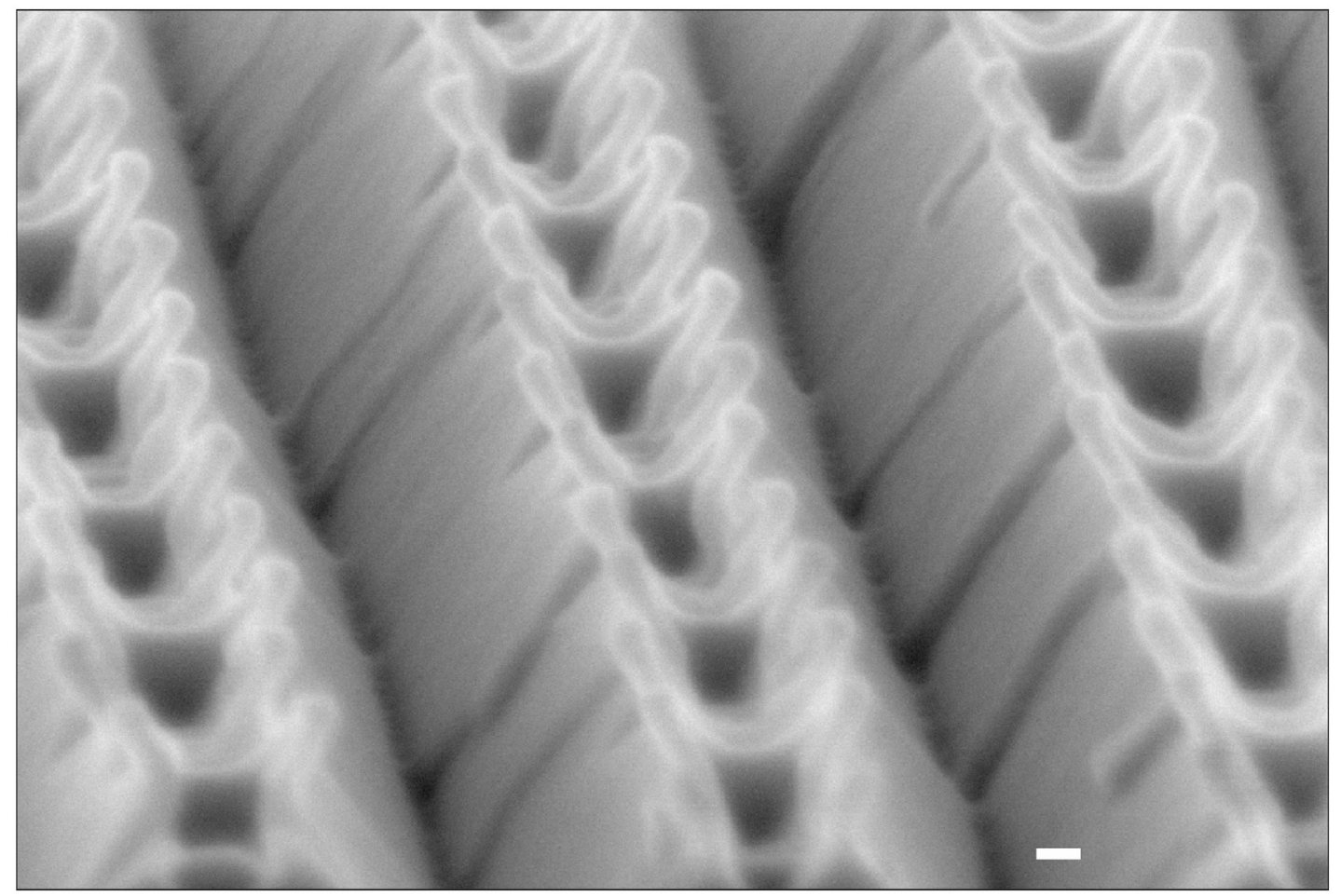

Figure 10. SEM image of silicon nanocrystals embedded from three sides in the $\mathrm{SiO}_{2}$ scaffold. $\mathrm{Cr}$ was deposited prior imaging to avoid charging. Scale bar is $20 \mathrm{~nm}$.

(i.e. a duty cycle below 50\%). However, as explained in the Experimental Methods section, it is important to have a duty cycle close to $50 \%$ for the formation of an ordered array of Si nanocrystals. Therefore, for the second DTL step an alternative lift-off procedure with $\mathrm{Cr}$ is utilized prior to BARC etching.

In this case the lift-off procedure has to be applied on top of the BARC layer. This implies that the 'conventional' procedure-i.e. a combination of lithography, deposition of a thin metal film and ultrasonic lift-off in acetone-cannot be used, since the BARC layer will dissolve in acetone upon exposure of the photoresist to this solvent. In order to avoid BARC dissolution, an alternative lift-off procedure is exploited. In fact, in photoresist developer OPD4262 the BARC layer does not dissolve. Moreover, if the patterned PFI88 layer undergoes a flood UV-exposure prior to metal deposition this PR is dissolvable in OPD4262.

In order to have a good outcome of this alternative liftoff procedure, several aspects have to be taken into account with respect to the deposition method, as well as the type of metal to be used. The deposition should be directional, for which reason evaporation is preferred. The metal should not 

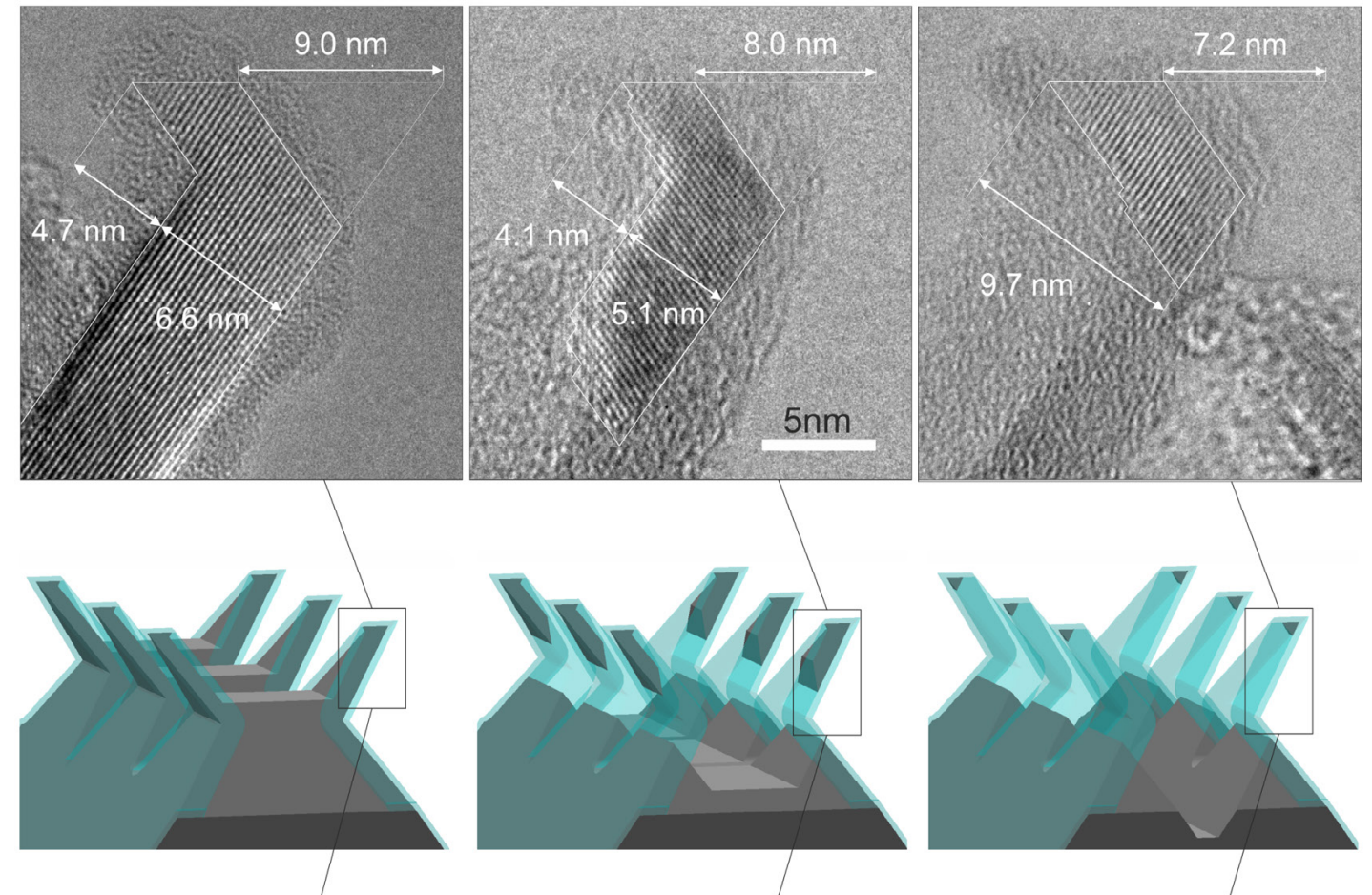

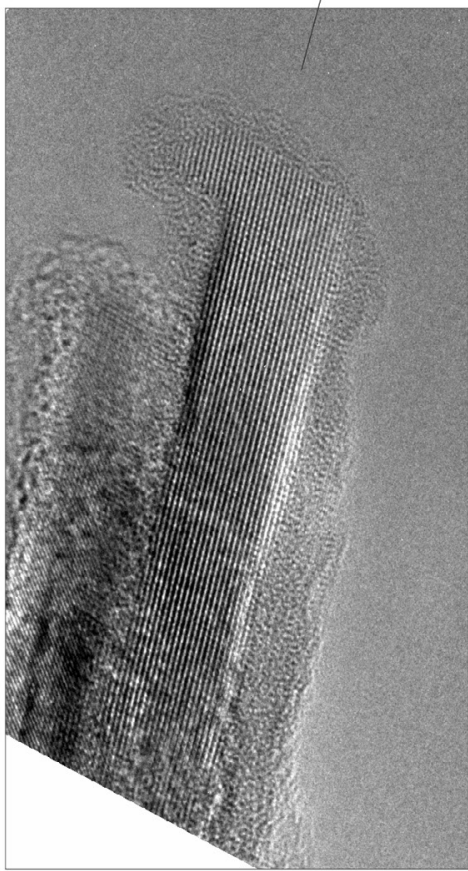

(a)

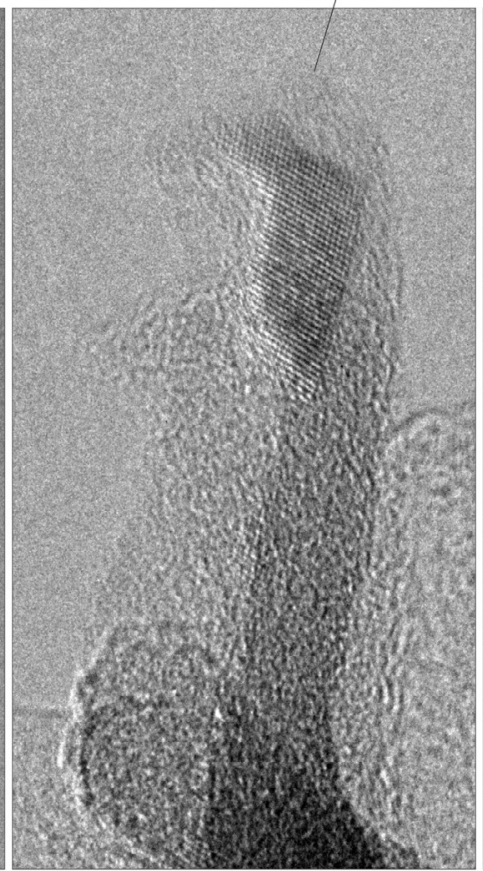

(b)

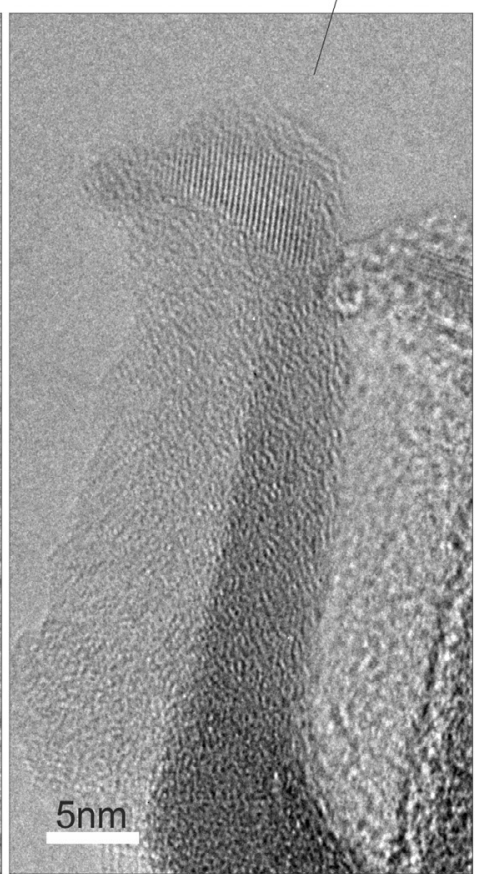

(c)

Figure 11. TEM images of final nanocrystals. At some locations fully developed sub- $15 \mathrm{~nm}$ nanocrystals have been formed (c), while at other locations some silicon is still present in the 'stem' of the 3D silicon oxide mask ((a) and (b)).

dissolve in OPD (thus aluminum is not suitable) and should have a high etch selectivity in the RIE-steps of the BARC as well as the $\mathrm{Si}_{3} \mathrm{~N}_{4}$ (see figures 3(f) and (g)). Moreover, it should also be possible to selectively remove this metal with respect to the PFI88 and BARC. Only an evaporated chromium film fulfills these requirements, and is hence applied (deposition parameters on a flat surface: Balzers BAK 600 system, pressure $10^{-6} \mathrm{mTorr}$, current $20 \mathrm{~mA}$, deposition rate $0.02 \mathrm{~nm} \mathrm{~s}^{-1}$ ).
It is found that the thickness of the evaporated $\mathrm{Cr}$ film is important. If a too thick film is deposited, i.e. $20 \mathrm{~nm}$, cracks appear in the $\mathrm{Cr}$ (figure 8(a)), resulting in masking failures and hence in an improper transfer of the line pattern into the BARC and/or $\mathrm{Si}_{3} \mathrm{~N}_{4}$. Such undesired cracks are not observed in a $10 \mathrm{~nm} \mathrm{Cr}$ film (figure 8(b)), and this thickness acts as a perfect film in the alternative lift-off procedure. The SEM images of figures 8(c) and (d) are taken after lift-off of $\mathrm{Cr}$ and after RIE etching of the BARC layer with $\mathrm{N}_{2}$. 


\subsection{Fabrication of nanocrystals}

In order to obtain nanocrystals after the second DTL nanolithography step, this second line pattern has to be transferred into the underlying $\mathrm{Si}_{3} \mathrm{~N}_{4}$. A crucial step is to fully open the bottom of the $\mathrm{V}$ - grooves in the directional RIE etching step of LPCVD $\mathrm{Si}_{3} \mathrm{~N}_{4}$. Due to a perfect conformal $\mathrm{Si}_{3} \mathrm{~N}_{4}$ layer in the V-grooves (black arrows in figure 9(a)) the thickness of the nitride is 1.73 times the thickness $(\mathrm{t})$ deposited on a (111)-plane (figure 7(a)). Therefore an etch factor of 2 was applied in the RIE $\mathrm{Si}_{3} \mathrm{~N}_{4}$ etching step followed by the third $\mathrm{KOH}$ etching step.

To check the etch rate of $\mathrm{Si}_{3} \mathrm{~N}_{4}$ before retraction EL, plain dummy wafers were added to the LPCVD process of $\mathrm{Si}_{3} \mathrm{~N}_{4}$. Except for the patterning step, similar processes were performed to these dummy wafers as to the device wafers. Just before the retraction etch of the device wafers, a dummy wafer was etched to determine the $\mathrm{Si}_{3} \mathrm{~N}_{4}$ etch rate in $50 \% \mathrm{HF}$, which was found to be $7.9 \pm 0.1 \mathrm{~nm} \mathrm{m^{-1 }}$ (5-point measurement, $10 \mathrm{~mm}$ edge exclusion). Figure 9 (b) shows the result after the third $\mathrm{KOH}$ etching step and a $7.9 \mathrm{~nm}$ silicon nitride retraction etching step. The height of the anvil structures is determined by half the depth $h$ of the doubled V-groove pattern (see figures 9(a) and also 2(d)). Based on the geometry we expect $h=60 \mathrm{~nm} / \tan \left(35.3^{\circ}\right)=85 \mathrm{~nm}$, thus a theoretical anvil height of $42.5 \mathrm{~nm}$. This calculated value matches well with the measured height of the anvil as determined from the SEM image taken at sample tilt angle of $45^{\circ}$. Thus, the height of the realized anvil is $\cos \left(45^{\circ}\right) \times 57 \mathrm{~nm}=40 \mathrm{~nm}$. While the result is not perfect in terms of achieved duty cycle (L/ $(\mathrm{L}+\mathrm{S}) * 100 \%>50 \%)$, the image indicates that a duty cycle of around $50 \%$ is within reach with the DTL-Cr procedure. Note also that a slightly enhanced retraction $\left(r^{1}\right)$ is observed at the apices compared to the retraction $(r)$ along the edges. A SEM image of the final devices with silicon nanocrystals embedded from three sides in the $\mathrm{SiO}_{2}$ scaffold is shown in figure 10. Retraction of the silicon nitride was $9.9 \mathrm{~nm}$. The final structures are investigated by transmission electron microscopy (figure 11). The crystalline $\mathrm{Si}$ surrounded by amorphous $\mathrm{SiO}_{2}$ can be clearly seen by TEM. TEM analysis was performed at different locations along the edge of a piece of the sample. The analysis shows that at some locations fully developed sub- $15 \mathrm{~nm}$ nanocrystals have been formed (figure 11(c)), while at other locations some silicon is still present in the 'stem' of the 3D silicon oxide mask (figures 11(a) and (b)). We attribute these remains to an incomplete removal of the $\mathrm{Si}_{3} \mathrm{~N}_{4}$ in step (g), figure 2, which are also visible in figure 10. A consequence of these residues is a local masking of the convex corner of the stem. The $\{111\}$ crystal planes (d-spacing is $0.313 \mathrm{~nm}$ ) can clearly be seen, initially not only in the apex but also in the 'stem' of the 3D silicon oxide mask.). Note also the apparent thinning of the silicon in the 'stem' region due to the final anisotropic etching step (in $20 \%$ $\mathrm{KOH}$ solution at room temperature), indicated by the $4.7 \mathrm{~nm}$ in figure 11(a). This thinning is indicative of a finite etch rate of about $0.5-1 \mathrm{~nm} \mathrm{~min}{ }^{-1}$ in the $\langle 111\rangle$-direction. Note also that the expected tetrahedral crystals appear to be etched from the apex, indicated by the triangles with side length of about $8 \mathrm{~nm}$ in figure 11. It appears that the silicon oxide (dry thermally grown at $1050^{\circ} \mathrm{C}$ ) mask, which was slightly thinned in $1 \%$ $\mathrm{HF}$ and $85 \% \mathrm{H}_{3} \mathrm{PO}_{4}$ etching steps has been opened at the apex. This could indicate that at these growth conditions the initial oxide at the apex is slightly thinner than the expected $13.9 \mathrm{~nm}$ based on the thickness at the $\{111\}$-planes. Further research into the exact oxide coverage of sharp tips at these growth conditions is needed to further clarify the TEM observations.

\section{Conclusion}

In conclusion, we have developed a procedure for the fabrication of ordered arrays of high-density crystalline silicon nanostructures by combining DTL and EL with anisotropic wet etching (employing $\mathrm{KOH}$ and TMAH) on wafer scale. The density of the silicon nanostructures is ca. $10^{10} / \mathrm{cm}^{2}$, which is a factor $>1000$ higher than previously reported tetrahedral structures. TEM analysis shows that sub- $15 \mathrm{~nm}$ size has been achieved at some locations in the array, while at other locations some silicon remained in the 'stem' of the freestanding nanostructures. The cause of this issue has been discussed and can be addressed by optimization of the selective nitride etching process in combination with the doubled V-groove duty cycle.

In future we will study the combination with CL $[17,18]$ and directional deposition methods to explore the possibility to individually contacting the crystalline silicon nanostructures in a wafer-scale process. High-density arrays in combination with individual contacting may find application in new optical sensing as well as electronic system concepts.

\section{Acknowledgments}

The authors would like to thank Harun H Solak (Eulitha AG) for the fruitful discussions on exposure settings and Toyota Technological Institute for travel support for K Sugimura. Rico Keim and Mark Smithers (MESA + NanoLab) are gratefully acknowledged for their help with the TEM and SEM analysis, respectively. The contribution by Hai Le-The (BIOS Lab-on-a-Chip group at the University of Twente) to the DTL processing is highly appreciated. W G vdW acknowledges financial support from the NWO-nano (STW) program, grant no. 11470 .

\section{ORCID iDs}

N R Tas (1) https://orcid.org/0000-0001-7541-4345

\section{References}

[1] Janz S, Löper P and Schnabel M 2013 Silicon nanocrystals produced by solid phase crystallisation of superlattices for photovoltaic applications Mater. Sci. Eng. B 178 542-50

[2] Wang G, Ji J and Xu X 2014 Dual-emission of silicon quantum dots modified by 9 -ethylanthracene J. Mater. Chem. C 2 1977-81 
[3] Shcherbyna L and Torchynska T 2013 Si quantum dot structures and their applications Physica E 51 65-70

[4] Dohnalová K, Gregorkiewicz T and Kusová K 2014 Silicon quantum dots: surface matters J. Phys.: Condens. Matter 26173201

[5] Canham L T 1990 Silicon quantum wire array fabrication by electrochemical and chemical dissolution of wafers Appl. Phys. Lett. 57 1046-8

[6] Trwoga P F, Kenyon A J and Pitt C W 1998 Modeling the contribution of quantum confinement to luminescence from silicon nanoclusters J. Appl. Phys. 83 3789-94

[7] Hafsi N et al 2015 Photoluminescence from silicon nanocrystals embedded in silicon nitride fabricated by low-pressure chemical vapor deposition followed by hightemperature annealing J. Appl. Phys. 117063105

[8] Walters R J, Bourianoff G I and Atwater H A 2005 Field-effect electroluminescence in silicon nanocrystals Nat. Mater. 4 143-6

[9] Dohnalova K et al 2013 Surface brightens up Si quantum dots: direct bandgap-like size-tunable emission Light Sci. Appl. 2 e 47

[10] Wilson H F, McKenzie-Sell L and Barnard A S 2014 Shape dependence of the band gaps in luminescent silicon quantum dots J. Mater. Chem. C 2 9451-6

[11] Valenta J, Juhasz R and Linnros J 2002 Photoluminescence spectroscopy of single silicon quantum dots Appl. Phys. Lett. 80 1070-2

[12] Berenschot J W et al 2009 Chemically anisotropic singlecrystalline silicon nanotetrahedra Nanotechnology 20475302

[13] www.eulitha.com/fileadmin/images/PhableR_100/eulitha_ phabler100.pdf
[14] Solak H H, Dais C and Clube F 2011 Displacement Talbot lithography: a new method for high-resolution patterning of large areas Opt. Express 19 10686-91

[15] Hashiguchi G et al 1993 Wedge-shaped silicon emitter fabricated by new method Japan. J. Appl. Phys. 326291

[16] Zhao Y et al 2009 Sub-10 nm silicon ridge nanofabrication by advanced edge lithography for NIL applications Microelectron. Eng. 86 832-5

[17] Sarajlic E et al 2005 Fabrication of 3D nanowire frames by conventional micromachining technology The 13th Int. Conf. on Solid-State Sensors, Actuators and Microsystems, 2005. Digest of Technical Papers. TRANSDUCERS'05

[18] Berenschot E J W et al 2012 3D nanofabrication of fluidic components by corner lithography Small 8 3823-31

[19] Le-The $\mathrm{H}$ et al 2016 Shrinkage control of photoresist for large-area fabrication of sub- $30 \mathrm{~nm}$ periodic nanocolumns Adv. Mater. Technol. 21600238

[20] Berenschot J W, Jansen H V and Tas N R 2013 Fabrication of 3D fractal structures using nanoscale anisotropic etching of single crystalline silicon J. Micromech. Microeng. 23055024

[21] Kozhummal R et al 2012 Fabrication of micron-sized tetrahedra by $\operatorname{Si}\langle 111\rangle$ micromachining and retraction etching lithography $J$. Micromech. Microeng. 22085032

[22] Vangbo M et al 1996 Precise mask alignment to the crystallographic orientation of silicon wafers using wet anisotropic etching J. Micromech. Microeng. 6 279-82

[23] Kim G et al 2002 Replication molds having nanometer-scale shape control fabricated by means of oxidation and etching J. Nanosci. Nanotechnol. 3 55-9 